\title{
Quality Control of Invisible Defects in the Laminating Process using a New Thermographic Online System
}

\author{
V. Märgner ${ }^{*}$, H. El-Abed ${ }^{*}$, P. Meinlschmidt ${ }^{*}$, F. Schlüter ${ }^{* *}$ \\ *, Institute for Communications Technology, Schleinitzstr. 22, D-38092 Braun- \\ schweig, Germany \\ ** Wilhelm-Klauditz-Institut, Fraunhofer-Institute for Wood Research, \\ Bienroder Weg 54E, D-38108 Braunschweig, Germany
}

\begin{abstract}
A new thermographic online system for quality control in the laminating process is presented in this paper. The developed online system allows a $100 \%$ control of the laminating process of wood-based panels. Different types of invisible defects can be selected for detection. The system is implemented on a standard PC and tested in an industrial production process of particle boards with a transportation speed of about $50 \mathrm{~m} / \mathrm{min}$. A processing speed of $12 \mathrm{images} / \mathrm{sec}$ was reached and in the case of a detected fault an alarm message is sent to the operational personnel.
\end{abstract}

\section{Introduction}

The laminating process of wood-based panels with surface materials such as decor foils, HPL (high pressure decorative laminate) and melamine films is a well established method. Nevertheless, insufficient bonding or invisible defects below the surface are regularly recurring problems in quality assurance.

In a project supported by "Stiftung Industrieforschung" a thermographic online defect detection system was developed. The system should automatically detect with high accuracy invisible defects inside the particle boards as well as in the boundary layer between surface and the base material. The measurement system (see Fig. 1) is based on the principle of passive online thermography.

\section{The thermography technique}

Infrared thermography is a fast and non-destructive testing and evaluation method that can rapidly scan and interrogate large surface areas for internal (invisible) defects and structural faults [1-2].

If material is heated with infrared radiators, the temperature of the surface will rise suddenly. The speed at which the heat front is subsequently dissipated depends on different thermal properties of the material such as density, heat capacity, thermal conductivity and the bonding quality between top surface layer and the base material. A defect in the sub-surface creates a barrier for the heat diffusion process and, therefore, the surface temperature above the defect will decrease more slowly than the temperature in other regions. The region above such a defect will show a hot area much longer than the surrounding containing good quality bonding. The principle of this effect is shown schematically in Fig. 2. 
http://dx.doi.org/10.21611/qirt.2004.035

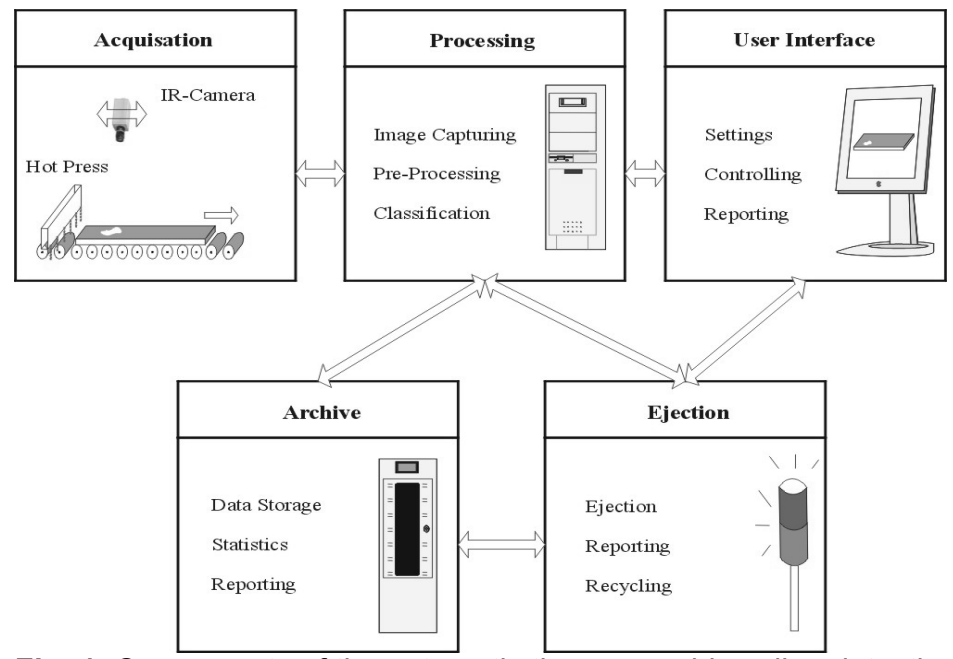

Fig. 1. Components of the automatic thermographic online detection system

Obviously, the differently decreasing temperatures are caused by different heat dissipation rates. Usually in wood-based-materials the defects can be detected within a few seconds to some minutes after the heat impact depending on the material and depth of the defect [3]. The different heat dissipation progress into the object shows up, sometimes in very complicated (Figure 3, left) or in very simple surface temperature pattern (Figure 3, right).
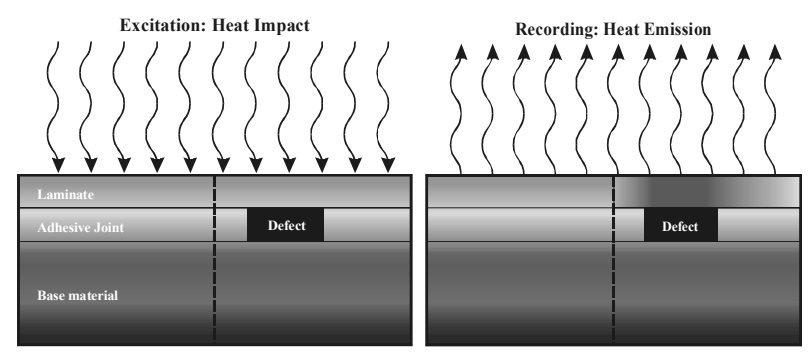

Fig. 2. Schematic drawing of the principle of infrared thermography, showing the uniformly distributed heat impact on the surface (left), the recorded heat emission (right) and the warmer region (dark) on the surface above the defect.
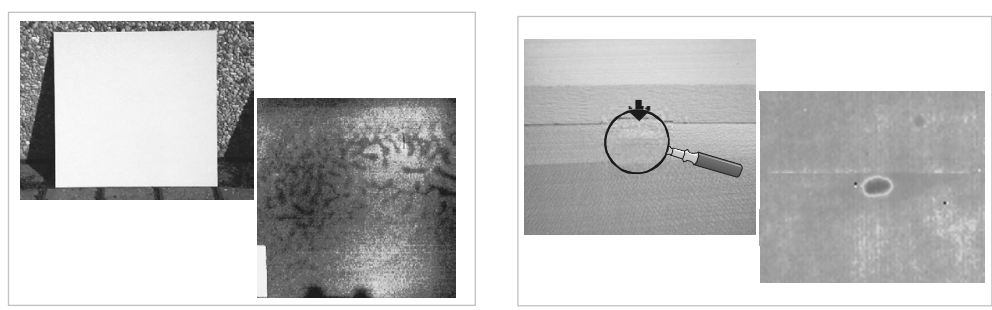

Fig. 3. A complicated thermographic image for the case of glass-reinforced plastic bonded to a particle board using polyurethane adhesive (left), and a simple debonding pattern in the case of veneered plywood table board (right). 


\section{Active in-line thermography}

At the Wilhelm-Klauditz-Institute a special active thermography set-up is used for the inspection of defective material. It is shown schematically in Figure 4 [4].

The material under inspection is placed on a conveyor-belt that can transport the samples with speeds up to $50 \mathrm{~m} / \mathrm{min}$. By moving the material along three infrared radiators the surface samples are heated homogeneously by a few degrees centigrade. During the further transport the heat penetrates into the material and the infrared-camera, which is placed above the conveyor-belt, records the thermographic images of the surface.

The very high temperature resolution of $0.02 \mathrm{~K}$ allows to detect with high accuracy

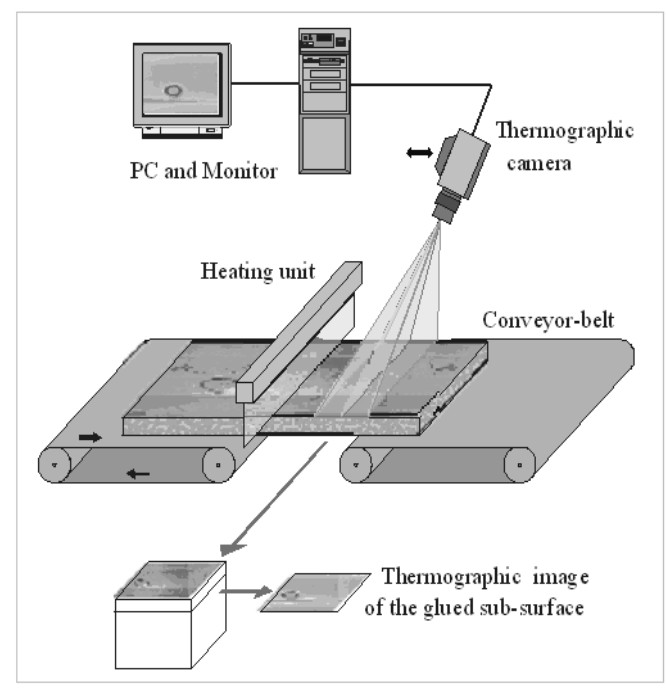
even defects and structural faults deep within the material. This depends on the thermal properties of the test material, the speed of the conveyor-belt and the distance between the heat source and the camera position.

For all thermographic investigations a highly sensitive focal plane area (FPA) camera was used (THERMOSENSORIK, $384 \times 288$ pixel) which works in the short wavelength band from 3,5-5 $\mu \mathrm{m}$.

Fig. 4. Schematic drawing of the thermographic set-up for the detection of debondings and structural faults within the laminated material

\section{Industrial application of passive thermography}

For measurements in industrial production lines the thermographic camera was positioned on a steel frame approximately $4 \mathrm{~m}$ above the conveyor-belt (Figure 5). This large distance was necessary to observe the full width of the laminated material by using a $28 \mathrm{~mm}$ camera lens without too much of optical distortion.

The measurements were carried out immediately behind the laminating press to use the production heat. Locally different temperatures, like cold and hot spots observed on the surface, indicate defects either within the bonding or in the carrier material.

The surface temperatures of the laminated wood-based panels were approximately $40{ }^{\circ} \mathrm{C}$ for the bonding with casein cold glue and $50{ }^{\circ} \mathrm{C}$ for urea resin glue in the measuring position. For boards with a width up to $120 \mathrm{~cm}$ the camera detects defects of $15 \mathrm{~mm}$ minimum size. 


\section{http://dx.doi.org/10.21611/qirt.2004.035}

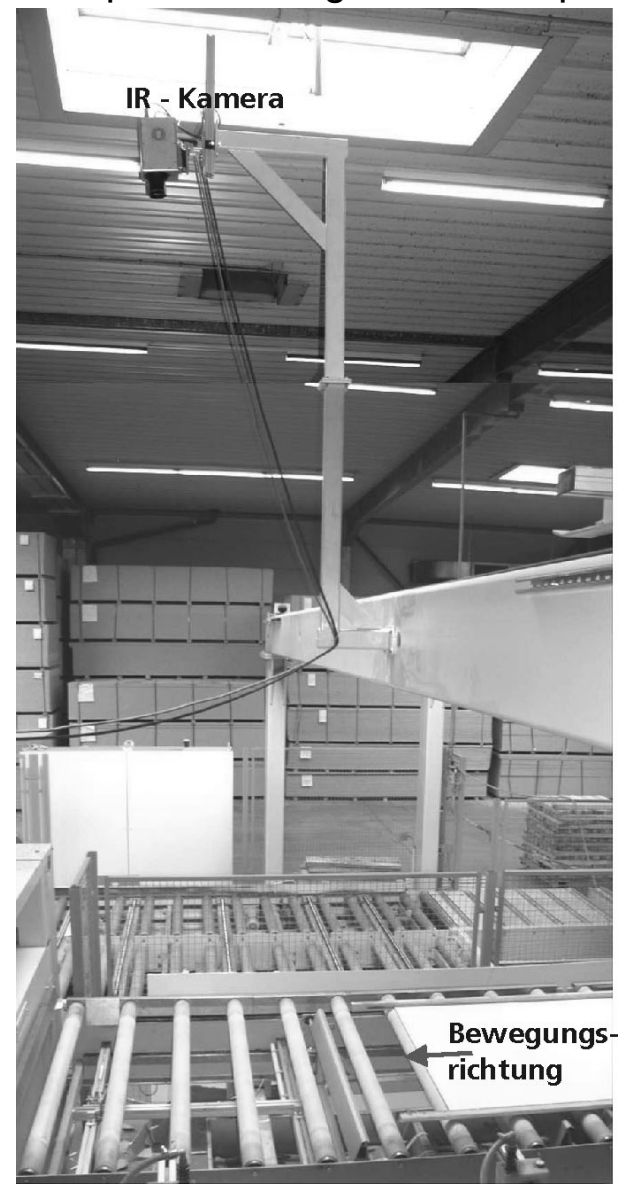

As for the laminations on particle boards (thickness of 3 to $38 \mathrm{~mm}$ ) investigations were carried out with a rate of speed of 20 to $30 \mathrm{~m} / \mathrm{min}$. Here, besides damages caused by fork lifts occurring at the edges of the boards, also local dents of $<1 / 10 \mathrm{~mm}$ in the surface, double-layer bonding of paper and splitting in the particle board could be detected.

When laminating of plywood boards the fallen off branches in the middle layer and the faulty gluing at the veneer joints became especially obvious.

Fig. 5. Thermographic set-up just behind a paper laminating press. By moving the material along the infraredcamera possible defects can be detected.

\section{The automatic inspection system}

The components of the implemented software system are shown as a simplified block diagram in figure 6 . Each block in this software system stands for an independent part of the system, connected to other parts by an interface. A further important interface is the user interface, which is used for controlling and observing the parameters and the correct operation of the system. The concept of the realized overall

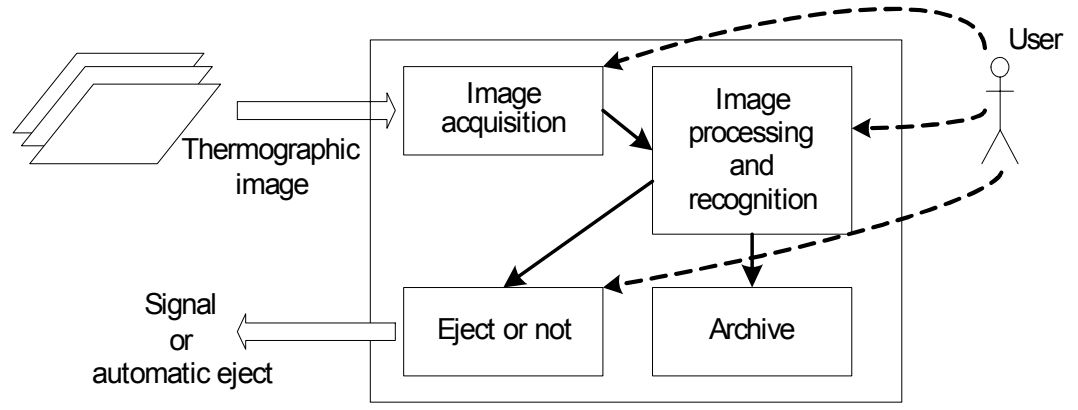

Fig. 6. Typical components of the overall software system 
software system was developed using UML (Unified Modelling Language) $[7,13]$ for real time systems.

\section{Image processing and recognition}

Thermography allows the visualisation of invisible defects as aforementioned. The next important step in realising a complete inspection system is the implementation of a digital image processing and recognition system, which analyses the thermographic images captured online during the production process.

Therefore a pre-processing step firstly performs noise filtering and shading correction $[5,6]$. Both are typical effects, known from thermographic images. The sensor produces some salt and pepper noise coming from sensor defects and shadings is produced by lens aberrations and non-uniform heating of the material in the field of the camera view. Furthermore, in a second step the separation of the board to be inspected from the uninteresting surrounding background is performed. This step can be made on the basis of a Hough transformation [9]. Thirdly a feature extraction process has to be implemented using different types of gradient filters, morphological filters and rank order functions [10,12].

Finally a detection method is implemented which considers the inhomogeneous temperature distribution across the board in the field of vision of the thermographic camera and the changing of the absolute temperature during production process. Different kinds of adaptive thresholds are used for automatic detection of defects $[8,11]$.
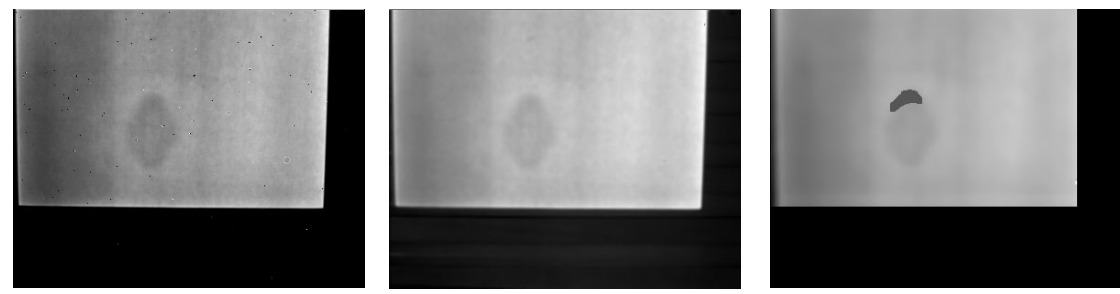

Fig. 6. Thermographic image of a paper laminated particle board with defect (splitting) (left), the pre-processed image (central) and the defect detection (right).

\section{Experiments and results}

Many different adhesion defects and structural faults can be detected using this system. An example of a splitting fault is shown in Figure 6. This defect occurred about $19 \mathrm{~mm}$ deep within the particle board with a size of $1.200 \mathrm{~mm}$ width and $2.500 \mathrm{~mm}$ length running with a transportation speed of $50 \mathrm{~m} / \mathrm{min}$. This defect not visible on the surface, can be clearly seen in the thermographic image (Fig. 6, left), can be preprocessed (Fig. 6, centre), and can be marked as removable board (Fig. 6, right). Here the high gradient on the upper side of the defect is the feature exceeding an adaptive threshold.

The introduced system provides fast and robust thermographic detection results. Moreover, the tests performed in the industrial production process showed that the image processing and recognition runs fast enough to follow the speed of the production. Using only one PC with a $2.6 \mathrm{GHz}$ processor to control the whole system, an average speed of 12 images/sec and an average processing time of $90 \mathrm{~ms} / \mathrm{image}$ were reached during a test in an industrial environment. The frame rate of the thermographic camera was set to 4 frames/sec that means an online control with overlapping images is possible. Table 1 shows the mean time/image for different series. 
http://dx.doi.org/10.21611/qirt.2004.035

\begin{tabular}{|l|c|c|c|c|c|c|c|}
\hline series & 01 & 02 & 03 & 04 & 05 & 06 & 07 \\
\hline \# of images & 1000 & 1000 & 1000 & 211 & 100 & 1000 & 107 \\
\hline ms/image & 90,07 & 89,98 & 89,92 & 87,86 & 88,14 & 89,56 & 89,59 \\
\hline
\end{tabular}

Tab. 1: Mean processing time for different series from industrial lamination process In our current work we are working on more sophisticated features to broaden the application field of the online system.

\section{Conclusion}

After successfully finishing the first tests in the industry, it will soon be possible to introduce thermographic inspection systems to the wood-based panel industry for the detection of defects within the production process. The results of the thermographic testing can be used to mark the debonded areas or to remove the material completely from the assembly line. Depending on the price of infrared-cameras and its robustness to work in the rough environment without too much maintenance, the acceptance of companies will increase to use thermography as a possible tool of quality control.

\section{Acknowledgment}

This research work is a funded project, financed and supported by "Stiftung Industrieforschung".

\section{REFERENCES}

[1] GAUSSORGUES G. (1994), Infrared Thermography, Chapman \& Hall, Microwave Technology Series 5, ISBN 0-412-47900-1

[2] MALDAGUE X.P.V. (1993). Nondestructive evaluation of materials by infrared thermography: Springer Verlag, London, ISBN 3-540-19769-9

[3] SEMBACH J., WU D., SALERNO A., HORA G. and BUSSE G. (1997). Nondestructive evaluation of delaminations in laminated wood-based panels by thermographical inspection tools: NDT Workshop, Llandudno: 41-48

[4] MEINLSCHMIDT P., SEMBACH J. (1999). Industrial thermographic inspection of delaminations in laminated wood-based panels, Third European workshop on non-destructive testing of panel products, October 1999, Llandudno, UK

[5] C. Demant, B. Streicher-Abel, P. Waszkewitz; „Industrielle Bildverarbeitung Wie optische Qualitätskontrolle wirklich funktioniert"; Springer Verlag; 1997

[6] R. C. Gonzalez, R. E. Woods; „Digital Image Processing“ ;Pearson Education.

[7] B. Oestereich; „Objekt-orientierte Software-entwicklung - Analyse und Design mit der Unified Modeling Language“; Oldenburg Verlag; 1998

[8] Otsu, N.: A Threshold Selection Method from Gray-Level Histograms, in IEEE Transactions on Systems, Man, and Cybernetics, Vol. SMC-9, No. 1, 01. 1979

[9] Jähne, B.: Digitale Bildverarbeitung, Springer Berlin Heidelberg, 1997

[10] Zamperoni, P.: Feature extraction by rank-order filtering for image segmentation, International Journal of Pattern Recognition and Artificial Intelligence 2, 1988, S. 301-319

[11] Chen, C.H., Pau, L.F., Wang, P.S.P.: Handbook of Pattern Recognition and Computer Vision, World Scientific, 1998

[12] Francesco G.B. De Natale Rank-order functions for the fast detection of texture faults International Journal of Pattern Recognition and Artificial Intelligence 10 (1996) 971-984

[13] Powel Douglass B.: Real-Time UML - Developing Efficient Objects For Embedded Systems, Addison-Wesley, 1999 